\title{
Attitudes about working beyond normal retirement age: The role of mandatory retirement
}

\author{
Jaap Oude Mulders ${ }^{1}$ \\ ${ }^{1}$ Netherlands Interdisciplinary Demographic Institute (NIDI-KNAW) / University of Groningen \\ E-mail: oudemulders@ nidi.nl
}

This is an author-produced PDF of an article published in Journal of Aging \& Social Policy. The published version is available online at:

http://dx.doi.org/10.1080/08959420.2018.1563473

\begin{abstract}
The Dutch government abolished mandatory retirement for national-level civil servants in 2008, but not for employees in other sectors. This study analyzes whether national-level civil servants have different attitudes and plans about working beyond normal retirement age than employees in other sectors. Results show no clear differences between the groups. A national ban on mandatory retirement would presumably not lead to much more older workers continuing to work beyond normal retirement, but would need to be integrated in a much broader policy reform that also addresses employment protection legislation and seniority-based wages.
\end{abstract}

\section{Keywords}

Older workers; Employment; Retirement; Civil servants; Workforce; The Netherlands 


\section{Introduction}

Employment in later life and retirement have changed significantly over recent decades in industrialized countries. In response to aging populations, many countries have implemented policy changes to prevent early exit of older workers and instead encourage longer working lives in an attempt to keep pension systems financially sustainable. As a result, older workers' employment participation rates and retirement ages have increased substantially. In addition to more participation before normal retirement age ${ }^{1}$, working beyond normal retirement age, either by continuing in the main 'career job' or by taking up a less demanding 'bridge job', is also increasingly prevalent (Dingemans et al., 2017; Pleau \& Shauman, 2013). Although there has been some opposition to the policy reforms that have led to longer working lives, there is also evidence that current cohorts of employees have adapted to the changed institutional context of longer working lives: Hess (2017) shows that preferred retirement ages have increased significantly in 12 European countries between 2003 and 2010.

While longer working lives are encouraged and facilitated for the largest part, in many countries there remains an important potential obstacle to employment participation at higher ages in the form of mandatory retirement, which allows employers to dismiss older workers without costs upon reaching a certain age. Even though usually a new contract can be negotiated if both employer and employee want to continue the employment relationship (Bal et al., 2012; Oude Mulders et al., 2014), mandatory retirement may obstruct people from working beyond normal retirement age because it ends the employment relationship and creates expectations for retirement and suggests a social norm that individuals above a certain age should not work (Radl, 2012). Although some countries have outlawed mandatory retirement, it is still a common practice in large parts of the world (Wood et al., 2010). It remains, however, a point of 
contention as population aging continues and countries are looking to prolong working lives. For example, in 2013 the European Parliament recommended that "Member States, in consultation with relevant partners, put a ban on mandatory retirement when reaching the statutory retirement age, so as to enable people who can and wish to do so to choose to continue to work beyond the statutory retirement age or to gradually phase in their retirement, as extending the period of premiums paid while at the same time shortening the period of benefit eligibility can help workers reduce any pension gaps at a fast pace" (European Parliament, 2013). At the same time, however, it is acknowledged that outlawing mandatory retirement altogether may not be as straightforward as it seems. Employers are often opposed to abolishing mandatory retirement, and in many countries mandatory retirement is an integral part of the institutional framework, making it infeasible to abolish mandatory retirement without also reforming employment protection legislation and seniority-based wage schemes (Gomez et al., 2002; OECD, 2017b).

But is mandatory retirement really an impediment to longer working lives? The Netherlands is an interesting case study that may help increase our understanding of the role of mandatory retirement and its abolishment on attitudes regarding retirement and working beyond normal retirement age. Mandatory retirement is a common practice in the Netherlands, and applies to virtually all employees in wage-and-salary employment. One notable exception, however, are employees of the state itself. In 2008 the government of the Netherlands stopped enforcing mandatory retirement on its national-level civil servants, in an attempt to promote longer working lives and set an example for other industries in the transition from an early-exit culture to longer working lives.

The objective of this study is to analyze whether, several years after the reform, older national-level civil servants have different preferences and expectations about working in later 
life, including working beyond normal retirement age, compared to older workers in other sectors. I use data from a 2015 survey into work and retirement issues among Dutch older workers from five different sectors.

This study contributes to the literature on retirement timing and mandatory retirement in two main ways. First, the abolishment of mandatory retirement in the Netherlands in one specific sector - national government - has created a unique natural experiment that may provide insights about the way in which mandatory retirement shapes attitudes and plans about work in later life, especially in the period beyond normal retirement age. Comparing preferences and expectations about retirement ages of older workers from different sectors sheds light on the role that mandatory retirement plays in this process. Second, studying plans and expectations about retirement timing in the Netherlands is interesting because the country is at the forefront of transitioning from having a strong early exit culture to having one of the highest normal retirement ages in the future (OECD, 2017a). Also, it has very different labor market institutions than other countries that have abolished mandatory retirement. Indeed, most studies into the effects of the abolishment of mandatory retirement have been situated in countries with a liberal welfare state model, such as the United Kingdom, United States, and Canada (Adams, 2004; Beck \& Williams, 2015; Shannon \& Grierson, 2004; Warren \& Kelloway, 2010). In contrast, the Netherlands is a country with characteristics of both the corporatist and social democratic welfare state models (Cousins, 2005), which may affect the role of mandatory retirement within the broader institutional framework. 


\section{Retirement Timing and Mandatory Retirement}

Retirement timing is a complex process that has been linked in the literature to a large number of antecedents and consequences. Its antecedents are, most commonly, found in individual factors, such as health, economic factors (e.g., income, wealth) and demographic characteristics (e.g., gender, age), but also the relation between retirement timing and familyrelated factors (e.g., marital status), work-related factors (e.g., employment history) and sociocultural factors (e.g., retirement age norms) has been explored (Fisher et al., 2016). Working beyond normal retirement age has mostly been related to similar antecedents, with also a strong focus on the role of motivational factors, such as working mainly for financial reasons, for personal satisfaction, for the social embeddedness of work, or for passing on knowledge to a future generation (Burkert \& Hochfellner, 2017; Fasbender et al., 2016; Mor-Barak, 1995). An important moderating factor that influences both retirement timing and working beyond normal retirement age is the institutional context in which the retirement transitions takes place, encompassing factors such as the availability and eligibility age for a public pension, the strength of employment protection legislation, and, the main focus of the current study, the legality and occurrence of mandatory retirement.

Mandatory retirement regulations allow employers to dismiss employees without costs upon reaching a certain age - usually called normal retirement age. Theoretically, mandatory retirement can be understood by considering the relationship between wages and productivity during the career. As Lazear (1979) explains, in a long-term implicit contract between employer and employee, the employee earns less than their productivity would justify at younger ages, whereas they earn more than their productivity would justify at higher ages. This relation between wages and employee productivity keeps the worker motivated throughout the contract 
period. However, there must be a fixed age at which the contract ends to prevent older workers from 'overearning' indefinitely. This is especially important in countries with a high level of employment protection legislation, since there it can be difficult and costly to dismiss an older worker whose productivity is declining.

This conceptualization of mandatory retirement is not without problems. First, the development of productivity over the life course is not as clear-cut as the theory suggests, with older workers in many occupations displaying none or only a minor reduction in productivity (Skirbekk, 2004; Ng \& Feldman, 2008). Second, in the modern labor market, employees are much less likely to stay with a single employer for their entire career. Instead, modern careers are often characterized by shorter tenures with multiple employers, and overall more uncertainty and precariousness in labor relations (Kalleberg, 2009). Third, the practice of identifying a uniform age at which employees can be dismissed seems fundamentally at odds with anti-age discrimination legislation, which states that age cannot be used as a justification for differential treatment of individuals (Wood et al., 2010).

Internationally, mandatory retirement is a common practice in most developed and industrialized countries (OECD, 2017a; Wood et al., 2010). There are, however, also countries that have abolished mandatory retirement. In the United States, the mandatory retirement age was first increased from 65 to 70 in 1978, then abolished (with some exceptions) in 1986. Other countries that have abolished mandatory retirement more recently include Australia, Canada, Denmark, New Zealand, Poland, and the United Kingdom (Lain, 2017; OECD, 2017a). 


\section{Retirement and the Policy Context in the Netherlands}

As mentioned before, the Netherlands is at the forefront of transitioning from a country where early exit from the labor market was very common, to a country where early exit opportunities have been severely restricted and instead longer working lives are becoming increasingly prevalent (Visser et al., 2016). Although the pressure on the pension system is increasing due to population aging, and several reforms have been necessary to guarantee its long-term sustainability, the system works well to provide most people with decent retirement savings when they reach normal retirement age. Wage-and-salary employees and their employers are commonly obliged to save for retirement within occupational pension schemes, which, together with the state pension, aim to provide retirees with pension benefits of about $70 \%$ of their average earned wage during the career. This results in comparatively high pension income levels and very low levels of poverty among older people (OECD, 2017). This also means most people do not have to continue to work beyond normal retirement age to provide in their basic needs.

In the Netherlands, mandatory retirement is commonly applied in virtually all labor contracts or collective labor agreements (OECD, 2014). The age at which mandatory retirement can be enforced is linked to the age at which individuals start to receive state pension. This age was set to 65 until 2012, but, after a policy reform, started to rise gradually to reach 67 in 2021 . According to the reform, the public pension age will increase further according to new calculations made by Statistics Netherlands about life expectancy at age 65, so that the period that each generation on average receives state pension will remain stable at approximately 18 years (De Beer et al., 2017). The ages at which the current cohort of older workers will receive state pension are presented in Table 1. The increase of the normal retirement age in the 
Netherlands is part of a broader set of policy reforms that aim to promote labor market participation at higher ages and extend working lives, in order to alleviate the rising costs associated with population aging (Sonnet et al., 2014; Fleischmann \& Koster, 2016). This started in the mid 2000s, with several reforms to make early retirement much more unattractive, for example by making early retirement schemes actuarially neutral and restricting the access to disability and unemployment benefits. Another policy reform, introduced in 2016, offers individuals that work beyond normal retirement age more protection against unfair treatment and guarantees a minimum wage.

Table 1: Normal retirement ages in the Netherlands for the current cohort of older workers

\begin{tabular}{ll}
\hline Date of birth & Normal retirement age \\
\hline Before 1 January 1948 & 65 \\
Between 1 January 1948 and 1 December 1948 & $65+1$ month \\
Between 1 December 1948 and 1 November 1949 & $65+2$ months \\
Between 1 November 1949 and 1 October 1950 & $65+3$ months \\
Between 1 October 1950 and 1 July 1951 & $65+6$ months \\
Between 1 July 1951 and 1 April 1952 & $65+9$ months \\
Between 1 April 1952 and 1 January 1953 & 66 \\
Between 1 January 1953 and 1 September 1953 & $66+4$ months \\
Between 1 September 1953 and 1 May 1954 & $66+8$ months \\
Between 1 May 1954 and 1 January 1955 & 67 \\
Between 1 January 1955 and 1 October 1956 & $67+3$ months \\
\hline
\end{tabular}

Within the context of these policy reforms and the rapidly aging population, in 2008 the government decided to stop enforcing mandatory retirement age at age 65 (at that time still the normal retirement age) for its own employees. With this decision, the national government aimed to set the right example for other sectors in its way of dealing with the aging of its workforce and its approach to employees' retirement. After several work ability studies were conducted among 
older national-level civil servants, the government decided that the age of 65 was no longer a valid cut-off age to enforce mandatory retirement. They acknowledged that national-level civil servants above age 65 were, in general, still productive enough to keep contributing to their organizations, and should therefore get the right to remain employed, with no change in wage and employment conditions, for at least several years beyond normal retirement age. At the implementation of this directive in 2008, civil organizations and managers could technically still enforce mandatory retirement in specific circumstances such as organizational downsizing, but were actively encouraged to allow all requests for working beyond normal retirement age.

In 2014, this policy was formalized into law and organizations and managers could no longer refuse requests for working beyond normal retirement age. Under the current policy, national-level civil servants can work until age 70. After that, if they want to continue working, they can get one year contract extensions as long as there are no physical or mental barriers to continued work performance. National-level civil servants that continue to work beyond normal retirement age do so under the same terms of employment as before, meaning there is no drop in income or job level, as is often the case in the private sector (Oude Mulders et al., 2014). In fact, the net income of national-level civil servants that continue to work beyond normal retirement age increases, as they pay fewer taxes and start to receive their state pension. Mandatory retirement is only abolished for civil servants working at the national level, meaning for employees of ministries and any nationally operating civil agencies. Civil servants at other levels (i.e., the municipality or province levels) are still subject to mandatory retirement regulations. 


\section{Methods}

\section{Data}

The data stem from the first wave of the NIDI Pension Panel, collected between May and November 2015. The NIDI Pension Panel is a prospective cohort study among Dutch older workers (aged 60-65 at baseline) who are enrolled in three of the largest pension funds of the country, covering employees in the public sector, education, healthcare, welfare, and construction sectors. The sample was drawn through a stratified design. First, a sample of organizations that were covered by the three pension funds was drawn. Next, within these organizations, a random sample of older workers from the birth cohorts 1950-1955, who worked at least 12 hours a week, was drawn.

Selected older workers received a postal mailing of their pension fund with a letter introducing the research from the pension fund, a cover letter from the researchers, and a questionnaire with questions on their employment history, current employment, attitudes and plans towards retirement, and personal background. Respondents could also opt to fill in an online version of the questionnaire with a unique code that was in the accompanying letter. A total of 15,496 older workers were approached to participate in the survey, out of which 6,793 participated, for a response rate of $44 \% .341$ participants were classified as national-level civil servants. This is the only group of workers for whom mandatory retirement does not apply. The other participants were other civil servants (not at the national level; $n=1522$ ); and workers from the education $(n=1604)$, construction $(n=1333)$, healthcare $(n=871)$, and welfare $(n=$ 1222) sectors. 


\section{Measures}

Retirement plans are measured in two different ways. First, respondents were asked their preferred retirement age with the question "If you had a complete say in matters, what would be (or would have been) your age of retirement?" Second, expected retirement age is measured with the question "At what age do you expect to retire in your current job?" Conceptually, both measures tap into retirement timing. The preferred retirement age is, however, less susceptible to institutional or financial constraints than the expected retirement age. Still, the preferred retirement age gives useful information about the extent to which individual preferences and desires are obstructed by the institutional context (Hess, 2017; Hofäcker, 2015).

The central explanatory factor is sector, since national-level civil servants do not face mandatory retirement, whereas workers from all other sectors do. Several additional explanatory factors are controlled for in the analyses. First, sex of the older workers $(0=$ male; $1=$ female $)$. Second, age of the older worker (all between 60 and 65 due to sample design). Third, selfreported health, measured on a 5 -point scale $(1=$ very poor; $2=$ poor; $3=\operatorname{good} ; 4=$ very good; 5 $=$ excellent). Fourth, workers' educational level, categorized into three levels according to the International Standard Classification of Education (ISCED) classification (low = primary or lower secondary education; medium = upper secondary or post-secondary non-tertiary education; high $=$ tertiary education $)$. Fifth, partnership status $(0=$ single; $1=$ partnered $)$, and sixth, average number of hours worked per week without overtime. Table 2 provides descriptive statistics for the variables used in this study. 


\section{Table 2: Sample descriptive characteristics}

\begin{tabular}{lrr}
\hline & Mean or \% & S.D. \\
\hline Dependent variables & & \\
Preferred retirement age & 63.44 & 2.31 \\
Expected retirement age & 65.73 & 1.41 \\
Independent variables & & \\
Sex & & \\
$\quad$ Male & $55.16 \%$ & \\
Female & $44.84 \%$ & \\
Age & 62.02 & 1.61 \\
Health & & \\
$\quad$ Very poor & $1.30 \%$ & \\
$\quad$ Poor & $15.71 \%$ & \\
$\quad$ Good & $53.16 \%$ & \\
$\quad$ Very good & $20.53 \%$ & \\
$\quad$ Excellent & $9.29 \%$ & \\
Education & & \\
$\quad$ Low & $19.68 \%$ & \\
$\quad$ Medium & $32.83 \%$ & \\
$\quad$ High & $47.48 \%$ & \\
Partner & & \\
$\quad$ No & $18.52 \%$ & \\
Yes & $81.48 \%$ & \\
Hours worked & 31.56 & 8.08 \\
\hline
\end{tabular}

\section{Analysis}

First, I analyze differences in preferred and expected retirement ages between national-level civil servants and older workers from other sectors, first with descriptive statistics, then with ordinary least squares (OLS) regression analysis, including sector and control variables as explanatory variables. Studying only averages of preferred and expected retirement ages may, however, tell only part of the story, especially considering the institutional context. In countries where mandatory retirement at normal retirement age is common, working beyond this point requires an active decision on the part of the older worker. Therefore, secondly, I dichotomized the dependent variables, and determined for each older worker whether their preferred and 
expected retirement ages were higher than the normal retirement age (based on their date of birth; see Table 1). Because the normal retirement age for this cohort is rising rapidly, people may not exactly be aware of the normal retirement age that applies to them. Therefore, and also to study how many people want to continue working for a significant amount of time, I also calculated whether their preferred and expected retirement ages were at least six and twelve months higher than their normal retirement age. I then perform logistic regression analysis for preferring and expecting to work at least six months beyond normal retirement age, using sector and the control variables as explanatory variables.

\section{Results}

\section{Preferred and Expected Retirement Age}

Table 3 shows average preferred and expected retirement ages for older workers from the different sectors. The results show that, on average, the preferred and expected retirement ages of national-level civil servants do not differ strongly from older workers in other sectors. On average, the preferred and expected retirement ages of national-level civil servants do not differ from other civil servants and older workers in the educational sector. They are significantly higher than those for older workers in the construction sector. However, they are lower than those for older workers in the healthcare and welfare sectors. Another interesting finding is that expected retirement ages for all sectors are between 2 and 2.8 years higher than preferred retirement ages, and that expected retirement ages are higher than 65 in all sectors, which can be attributed to the increasing normal retirement age in the Netherlands. Still, also preferred retirement ages are higher than those reported for the Netherlands by Hess (2017) using data 
from 2010, reinforcing the finding that people adapt their preferences to changing context, but not as quickly as their actual expectations.

Table 3: Average preferred and expected retirement ages for different sectors

\begin{tabular}{|c|c|c|c|c|c|c|}
\hline & \multicolumn{3}{|c|}{ Preferred retirement age } & \multicolumn{3}{|c|}{ Expected retirement age } \\
\hline & Mean & & S.D. & Mean & & S.D. \\
\hline $\begin{array}{l}\text { National-level civil } \\
\text { servants }\end{array}$ & 63.38 & Ref. & 2.53 & 65.71 & Ref. & 1.43 \\
\hline Other civil servants & 63.52 & & 2.46 & 65.78 & & 1.34 \\
\hline Education & 63.56 & & 2.12 & 65.62 & & 1.45 \\
\hline Construction & 62.65 & $* * *$ & 2.42 & 65.49 & $*$ & 1.58 \\
\hline Healthcare & 63.73 & $*$ & 2.07 & 65.93 & $*$ & 1.32 \\
\hline Welfare & 63.89 & $* * *$ & 2.10 & 65.98 & $* * *$ & 1.26 \\
\hline
\end{tabular}

Note: Stars indicate significant difference from national-level civil servants (two-sided t-test). * $\mathrm{p}<0.05 ; * * \mathrm{p}<0.01 ; * * * \mathrm{p}<0.001$

Table 4 shows OLS regression results where preferred and expected retirement ages are regressed on sector and the other explanatory variables. The results show a similar pattern: preferred and expected retirement ages of national-level civil servants are higher than those for older workers in the construction sector, but lower than those in the healthcare and welfare sectors, meaning there are no clear differences in preferred and expected retirement ages between groups that face different mandatory retirement rules. Furthermore, women have a higher preferred retirement age than men, which is an unusual finding (cf. Hess, 2017). Older workers in good health and higher educated also have higher preferred retirement ages than those in poor health and lower educated. However, there are no effects of sex, health, and educational level on expected retirement age, implying that men, unhealthy and lower educated older workers do not see the opportunity to realize their preference for a lower retirement age. Additionally, it is interesting to see a positive effect of age on preferred retirement age, but a negative effect on 
expected retirement age. The former is a common finding, whereas the latter can be explained by the rapidly increasing state pension age for this cohort, which means that the oldest participants in this study will receive their public pension from age 65 and three months onwards, whereas the youngest participants in this study do so from age 67 and three months onwards (see Table 1). Finally, single people and those that work more hours per week have both higher preferred and expected retirement ages.

Table 4: OLS regression results for preferred and expected retirement age

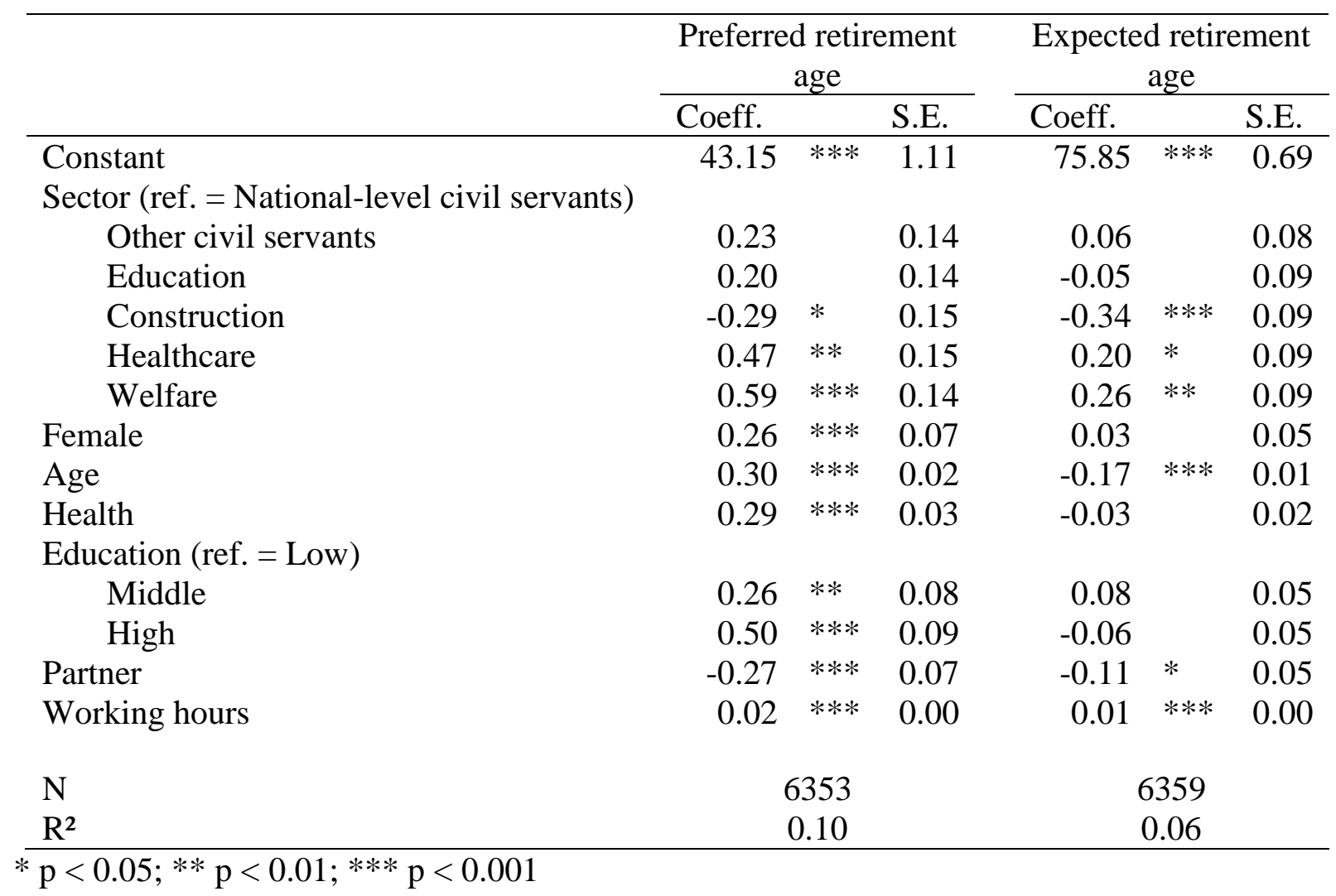

\section{Working Beyond Normal Retirement Age}

Table 5 shows, split per sector, whether older workers' preferred and expected retirement ages exceeded their normal retirement age at all, by at least six months, and by at least twelve 
months. The results show that preferring and expecting to work beyond normal retirement age are not very common: only about 7 per cent on average wants to continue working, whereas about 13 per cent on average expects to do so. However, the relatively strong decrease in people who expect to work beyond normal retirement age for at least six or twelve months shows that many people may not be exactly aware of the normal retirement age that applies to them, or that people only want to continue working for a few months beyond normal retirement age. Only a small minority prefers $(5 \%)$ or expects $(3 \%)$ to work at least one year beyond normal retirement age. Working at least six or twelve months beyond normal retirement age is relatively most popular among national-level civil servants. This may be the result of the policy change abolishing mandatory retirement for national-level civil servants, since older workers take the institutional context into consideration in their preferences and expectations about the future.

Table 5: Percentage of older workers that prefer and expect to work beyond normal retirement age

\begin{tabular}{|c|c|c|c|c|c|c|}
\hline \multirow[b]{3}{*}{$\begin{array}{l}\text { National-level civil } \\
\text { servants }\end{array}$} & \multicolumn{3}{|c|}{ Preferred retirement age > } & \multicolumn{3}{|c|}{ Expected retirement age > } \\
\hline & NRA & $\begin{array}{c}\mathrm{NRA}+6 \\
\text { months }\end{array}$ & $\begin{array}{c}\text { NRA + } \\
12 \\
\text { months }\end{array}$ & NRA & $\begin{array}{c}\mathrm{NRA}+6 \\
\text { months }\end{array}$ & $\begin{array}{c}\text { NRA + } \\
12 \\
\text { months }\end{array}$ \\
\hline & $8.80 \%$ & $7.92 \%$ & $7.33 \%$ & $13.20 \%$ & $8.21 \%$ & $4.99 \%$ \\
\hline Other civil servants & $7.69 \%$ & $6.37 \%$ & $5.19 \%$ & $11.24 \%$ & $5.32 \%$ & $2.43 \%$ \\
\hline Education & $8.17 \%$ & $6.80 \%$ & $5.86 \%$ & $10.91 \%$ & $5.17 \%$ & $2.87 \%$ \\
\hline Construction & $3.68 \%$ & $3.00 \%$ & $2.40 \%$ & $12.98 \%$ & $5.70 \%$ & $1.95 \%$ \\
\hline Healthcare & $7.46 \%$ & $5.86 \%$ & $5.05 \%$ & $16.42 \%$ & $8.27 \%$ & $3.33 \%$ \\
\hline Welfare & $8.47 \%$ & $7.31 \%$ & $6.33 \%$ & $15.86 \%$ & $7.75 \%$ & $3.65 \%$ \\
\hline
\end{tabular}

Note: NRA $=$ Normal retirement age (calculated based on date of birth)

Table 6 shows logistic regression results for preferring and expecting to work at least six months beyond normal retirement age. The results show that national-level civil servants are more likely than other civil servants and older workers in the construction sector to expect to work at least six months beyond normal retirement age. There is no significant difference, 
Table 6: Logistic regression results for working at least 6 months beyond preferred and expected retirement age

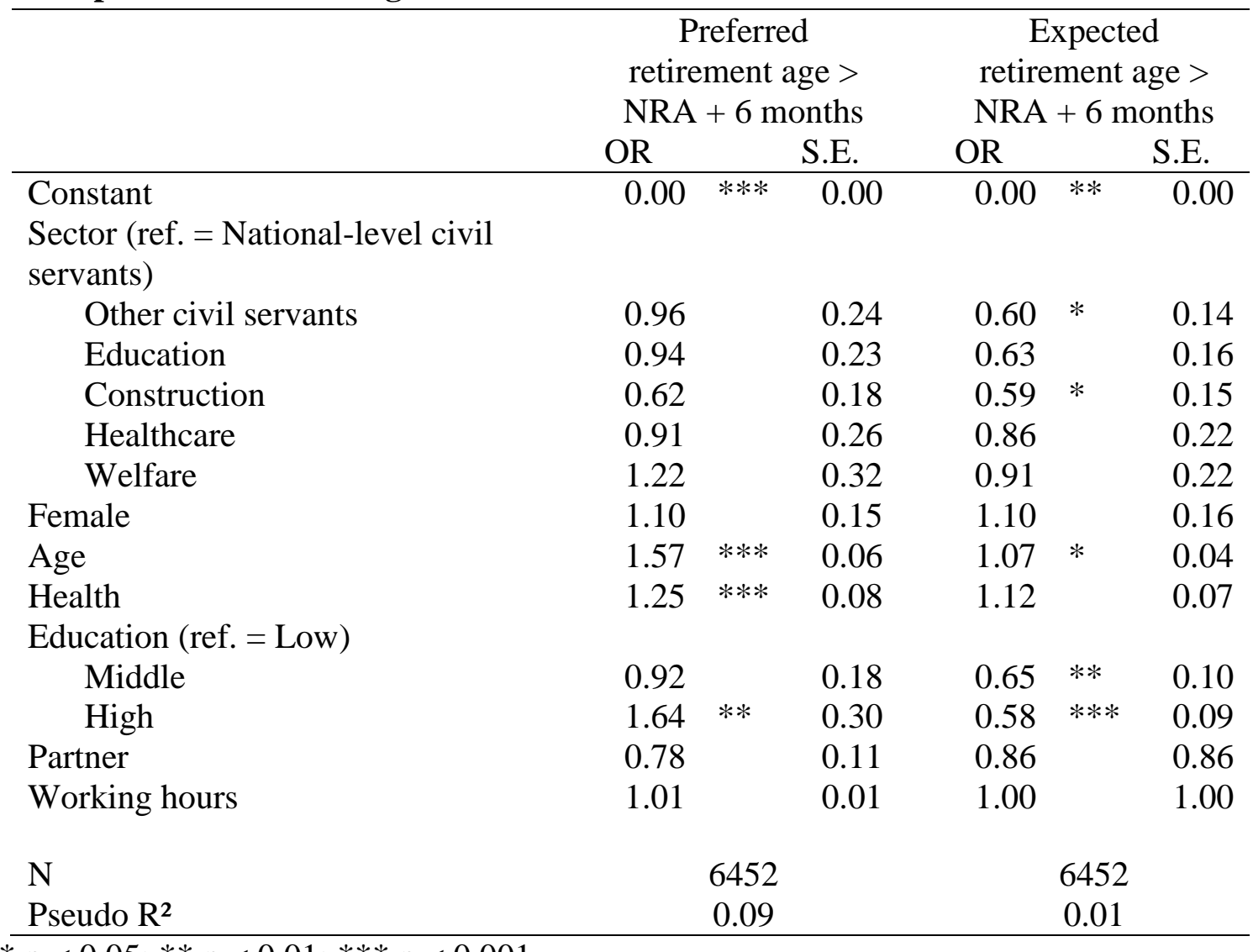

$* \mathrm{p}<0.05 ; * * \mathrm{p}<0.01 ; * * * \mathrm{p}<0.001$

Note: NRA $=$ Normal retirement age (calculated based on date of birth)

however, with older workers from the education, healthcare, and welfare sectors. There is also no significant difference when it comes to preferred retirement ages. Furthermore, age has a positive effect for both preferring and expecting to work at least six months beyond normal retirement age. This is most likely due to the normal retirement age already being higher for younger cohorts in this study, which makes them less likely to work beyond normal retirement age, even though on average their expected retirement age is higher (see Table 4). Finally, older workers with a low education have a lower likelihood of preferring to work at least six months beyond normal retirement age, but a higher likelihood of expecting to do so. This may be because they 
are uncertain about their retirement income, or expect it to be insufficient, forcing them to continue working past the barrier of normal retirement age.

\section{Discussion}

Although mandatory retirement is common for employees in the Netherlands, it was abolished for national-level civil servants in 2008. In this study, I analyzed whether, several years after the reform (in 2015), older national-level civil servants differed from older workers in other sectors in their attitudes and plans about retirement age and working beyond normal retirement age. The results showed no clear differences between groups that face different mandatory retirement rules. Although national-level civil servants had a higher preferred and expected retirement age than older workers in the construction sector, it was lower than those for older workers in the healthcare and welfare sectors. Older national-level civil servants do expect to work beyond normal retirement age somewhat more often than other civil servants and workers in the construction sector, but not more often than workers in the education, healthcare, and welfare sectors.

How do these findings relate to studies that have found a strong increase in employment participation rates after normal retirement age in countries such as the United States and the United Kingdom that have seen a national ban on mandatory retirement (cf. Adams, 2004; Lain, 2017)? Three factors can be identified. First, the broader institutional framework of the labor market in the different countries. Countries that have abolished mandatory retirement generally have low levels of employment protection legislation (Wood et al., 2010), which makes it comparatively easy for employers to dismiss employees with low productivity levels (Beck \& Williams, 2015). In contrast, the Netherlands has one of the highest levels of employment 
protection legislation, and its wage-setting procedures highly value seniority and tenure (OECD, 2014), making older workers relatively expensive and well-protected. These institutional factors are closely tied to the institution of mandatory retirement (Lazear, 1979; Gomez et al., 2002). Mandatory retirement, in other words, is an integral part of the Dutch labor market, and abolishing it in only one sector without also changing interrelated institutions does not seem to lead to large increases in employment beyond normal retirement age. This is also likely to apply to similar countries, especially in Europe, that have more corporatist and social-democratic rather than liberal labor market institutions and regulations. Abolishment of mandatory retirement without reforms to employment protection legislation and wage-setting procedures that value seniority may predominantly lead to employers becoming less likely to offer permanent positions to employees in general and older workers with uncertain productivity profiles in particular.

Second, social norms and the role that mandatory retirement plays in the institutionalization of social norms regarding retirement. Most people have relatively fixed ideas about the 'appropriate age to retire', which is anchored by institutions such as the eligibility age for state pension and the mandatory retirement age (Oude Mulders et al., 2017; Radl, 2012). Also, in the past two decades, the Netherlands has transitioned from having a strong 'culture of early retirement' to focusing on and facilitating longer working lives, evidenced by the increasing normal retirement age (see Table 1; Fleischmann \& Koster, 2016; OECD, 2017a). This means that current cohorts of older workers have seen earlier cohorts retire much earlier than is currently feasible, which has created some resentment (Van Solinge \& Henkens, 2017). In other words, current cohorts of older workers already need to work much longer than what used to be the norm in the country, which is likely to have a limiting effect on the number of older workers that want to continue working even further, beyond normal retirement age. In addition, given the 
much longer working lives, managers' support for even longer working lives, which is instrumental for working beyond normal retirement age (Wöhrmann et al., 2017) may be limited for the current cohort of older workers. This may, however, change in the future as longer working lives become the norm and both employees and managers get accustomed to working above age 65 . Since many other countries, especially those where mandatory retirement is common, have social norms that may not approve of working beyond normal retirement age (Radl, 2012), such social norms may impede people from working beyond normal retirement age, even if mandatory retirement would be abolished.

Third, the role of pensions and the financial necessity to work beyond normal retirement age. In countries that have abolished mandatory retirement, many people that work beyond normal retirement age do so for predominantly financial reasons (Burkert \& Hochfellner, 2017; Fasbender et al., 2016; Lain, 2017). In the Netherlands, virtually all wage-and-salary employees are covered by defined benefit pension plans and the state pension, leading to high pension replacement rates after normal retirement age (OECD, 2017a). This means there are hardly any older workers that need to continue working beyond normal retirement age to supplement their pension income, which in turn leads to a lower overall willingness to work beyond normal retirement age in the Netherlands (Dingemans et al., 2017). There is still a financial incentive to continue working beyond normal retirement age for national-level civil servants, since their net income increases substantially (due to lower taxes and receiving state pension) when they keep working. However, given their adequate pension savings, it seems unlikely that such financial incentives play a large role in their decision to continue working. This is likely to extend to older workers in other sectors as well, if mandatory retirement were to be abolished completely, since they commonly have similar pension savings. However, financial motives may play a bigger role 
for people with little wealth or that have earned a lower income over their career (such as blue collar workers), since pension income is related to the average income level during the career. However, relating back to the first issue discussed above, in case of a national ban on mandatory retirement, the wage-setting procedure may also be subject to change, and older workers would likely have to accept a lower wage to continue working after normal retirement age.

Does this mean the policy to abolish mandatory retirement for national-level civil servants in the Netherlands is a failure? No, it is still feasible that for the limited number that do want to continue working beyond normal retirement age, this policy makes that goal more easily attainable and more attractive. It is also likely that under the current policy, older national-level civil servants feel more agency in their retirement transition and are less likely experience involuntary retirement, which may benefit their well-being (Dingemans \& Henkens, 2014). However, in the case of a national abolishment of mandatory retirement, such positive effects may be moderated by the necessary accompanying weakening of employment protection legislation and seniority-based wages, which ultimately may harm the position of older workers in the labor market (Beck \& Williams, 2015; Gomez et al., 2002).

\section{Limitations}

Some limitations of this study need to be considered. First, I could only analyze older workers' attitudes and plans about working beyond normal retirement age cross-sectionally. Data on older workers' attitudes and plans before the state stopped enforcing mandatory retirement on its own employees in 2008 were not available, making it impossible to draw conclusions about the causal effect of the policy reform. Still, since working until and beyond normal retirement age was very uncommon in the Netherlands before the policy reform, and because there were no or only very minor differences in attitudes towards working beyond normal retirement age 
between national-level civil servants and the comparable group of other civil servants (e.g., at the municipality or province level), it does seem likely that the overall effects of the policy reform are very minor.

Second, like any study that analyzes retirement attitudes and plans among a group of older workers, there may be an issue with selection bias. Since the sample only includes older workers, individuals from the same cohort that left the workforce due to, for example, early retirement or disability were not included in the analysis. It may therefore be possible that sectoral differences in attitudes and plans about working beyond normal retirement age are not perfectly represented. Still, since premature exit from the labor market has become relatively uncommon in the Netherlands, all sectors are likely equally affected, meaning the impact on the overall results is probably minor. Future studies may try to enhance our insight into the effects of (the abolishment of) mandatory retirement further by using longitudinal data from a broader sample. Also, studies from countries that have recently abolished mandatory retirement, but differ in policy context from other countries that have abolished it, such as Denmark and Poland, could provide valuable insights.

\section{Conclusion}

Mandatory retirement is a common practice in the Netherlands, but was abolished specifically for national-level civil servants in 2008. No clear differences in preferred and expected retirement ages between national-level civil servants and workers from other sectors were found. There were also no clear differences in the likelihood of expecting to work beyond normal retirement age. A national ban on mandatory retirement would probably not result in much more older workers working past the normal retirement age for any significant amount of time, also considering that the normal retirement age is rising. Furthermore, a national policy 
reform would have to be integrated in a much broader reform that also changes employment protection legislation and seniority-based wages.

\section{Endnotes}

${ }^{1}$ Normal retirement age here is defined as the age at which individuals become (fully) eligible for receiving the state pension. In the Netherlands, this is the same age at which mandatory retirement can be enforced. It is therefore synonymous with terms such as standard retirement age, traditional retirement age, statutory retirement age, and state pension age.

\section{References}

Adams, S.J. (2004). Age discrimination legislation and the employment of older workers. Labour Economics, 11, 219-241.

Bal, P.M., De Jong, S.B., Jansen, P.G.W., Bakker, A.B. (2012). Motivating employees to work beyond retirement: A multi-level study of the role of I-deals and unit climate. Journal of Management Studies, 49, 306-331.

Beck, V., \& Williams, G. (2015). The (performance) management of retirement and the limits of individual choice. Work, employment and society, 29, 267-277.

Burkert, C., \& Hochfellner, D. (2017). Employment trajectories beyond retirement. Journal of Aging \& Social Policy, 29, 143-167.

Cousins, M. (2005). European Welfare States: Comparative Perspectives. London: Sage.

De Beer, J., Van Dalen, H.P., \& Henkens, K. (2017). Stijgt de AOW-leeftijd niet te hard? MeJudice.nl, published on March 11th 2017. http://www.mejudice.nl/artikelen/detail/stijgt$\underline{\text { de-aowleeftijd-niet-te-hard }}$ 
Dingemans, E., \& Henkens, K. (2014). Involuntary retirement, bridge employment, and satisfaction with life: A longitudinal investigation. Journal of Organizational Behavior, 35, $575-591$.

Dingemans, E., Henkens, K., \& Van Solinge, H. (2017). Working retirees in Europe: Individual and societal determinants. Work, Employment and Society, 31, 972-991.

European Parliament (2013). Resolution of 21 May 2013 on an Agenda for Adequate, Safe and Sustainable Pensions.

http://www.europarl.europa.eu/sides/getDoc.do?type=TA\&language=EN\&reference=P7-TA$\underline{2013-204}$

Fasbender, U., Wang, M., Voltmer, J.-B., \& Deller, J. (2016). The meaning of work for postretirement employment decisions. Work, Aging and Retirement, 2, 12-23.

Fisher, G.G., Chaffee, D.S., \& Sonnega, A. (2016). Retirement timing: A review and recommendations for future research. Work, Aging and Retirement, 2, 230-261.

Fleischmann, M. \& Koster, F. (2016). From early exit to postponing pension: How the Dutch polder model shapes retirement. In D. Hofäcker, M. Hess \& S. König (Eds.), Delaying Retirement: Progress and Challenges of Active Ageing in Europe, the United States and Japan (pp. 171-193). London: Palgrave Macmillan.

Gomez, R., Gunderson, M., \& Luchak, A. (2002). Mandatory retirement: A constraint in transitions to retirement? Employee Relations, 24, 403-422.

Hess, M. (2017). Rising preferred retirement age in Europe: Are Europe's future pensioners adapting to pension system reforms? Journal of Aging \& Social Policy, 29, 245-261.

Hofäcker, D. (2015). In line or at odds with active ageing policies? Exploring patterns of retirement preferences in Europe. Ageing \& Society, 35, 1529-1556. 
Kalleberg, A.L. (2009). Precarious work, insecure workers: Employment relations in transition. American Sociological Review, 74, 1-22.

Lain, D. (2017). Employment of workers aged 65 and over: The importance of policy context. In E. Parry \& J. McCarthy (Eds.), The Palgrave Handbook of Age Diversity and Work (pp. 475497). London: Palgrave Macmillan.

Lazear, E.P. (1979). Why is there mandatory retirement? Journal of Political Economy, 87, 1261-1284.

Mor-Barak, M.E. (1995). The meaning of work for older adults seeking employment: The generativity factor. The International Journal of Aging and Human Development, 41, 325344.

Ng, T.W.H., \& Feldman, D.C. (2008). The relationship of age to ten dimensions of job performance. Journal of Applied Psychology, 93, 392-423.

OECD (2014). Ageing and Employment Policies: Netherlands: Working Better With Age. Paris: OECD Publishing. http://dx.doi.org/10.1787/9789264208155-en

OECD (2017a). Pensions at a Glance 2017: OECD and G20 Indicators. Paris: OECD Publishing. http://dx.doi.org/10.1787/pension_glance-2017-en

OECD (2017b). Preventing Ageing Unequally. Paris: OECD Publishing. http://dx.doi.org/10.1787/9789264279087-en

Oude Mulders, J., Henkens, K., \& Schippers, J. (2017). European top managers' age-related workplace norms and their organizations' recruitment and retention practices regarding older workers. The Gerontologist, 57, 857-866. 
Oude Mulders, J., Van Dalen, H.P., Henkens, K., \& Schippers, J. (2014). How likely are employers to rehire older workers after mandatory retirement? A vignette study among managers. De Economist, 162, 415-431.

Pleau, R., \& Shauman, K. (2013). Trends and correlates of post-retirement employment, 19772009. Human Relations, 66, 113-141.

Radl, J. (2012). Too old to work, or too young to retire? The pervasiveness of age norms in Western Europe. Work, Employment and Society, 26, 755-771.

Shannon, M., \& Grierson, D. (2004). Mandatory retirement and older worker employment. Canadian Journal of Economics, 37, 528-551.

Skirbekk, V. (2004). Age and individual productivity: A literature survey. Vienna Yearbook of Population Research, 2, 133-153.

Sonnet, A., Olsen, H., \& Manfredi, T. (2014). Towards more inclusive ageing and employment policies: The lessons from France, the Netherlands, Norway and Switzerland. De Economist, $162,315-339$.

Van Solinge, H., \& Henkens, K. (2017). Older workers' emotional reactions to rising retirement age: The case of the Netherlands. Work, Aging and Retirement, 3, 273-283.

Visser, M., Gesthuizen, M., Kraaykamp, G., \& Wolbers, M.H.J. (2016). Trends in labour force participation of older men: Examining het influence of policy reforms, normative change and deindustrialization in the Netherlands, 1992-2009. Economic and Industrial Democracy, 37, $425-447$.

Warren, A.M., \& Kelloway, K.E. (2010). Retirement decisions in the context of the abolishment of mandatory retirement. International Journal of Manpower, 31, 286-305. 
Wöhrmann A.M., Fasbender, U., \& Deller, J. (2017). Does more respect from leaders postpone the desire to retire? Understanding the mechanisms of retirement decision-making. Frontiers in Psychology, 8(1400): 1-11.

Wood, A., Robertson, M., \& Wintersgill, D. (2010). A comparative review of international approaches to mandatory retirement. Department for Work and Pensions: Research Report 674. 